\title{
The problem of nonhuman agency and bodily intentionality in the Anthropocene
}

\section{Jonggab Kim ${ }^{1}$}

Published online: 17 April 2020

(c) The Author(s) 2020

\begin{abstract}
One of the vital issues in the discourse on the Anthropocene is the problem of material or bodily agency. Agency has long been the exclusive attribute of human consciousness and intentionality, but now the boundary between humans and nonhumans, mind and body, has become problematic. How might we reconceptualize agency? This article attempts to answer that question by working through Bruno Latour's posthuman configuration of agency. Latour's plea to reject not only consciousness but also intentionality conflicts with his animistic vision. What we need is not to dismiss intentionality in toto but to dehumanize it and acknowledge that there is a nonhuman form of intentionality. The intentionality that he wrongly paired with consciousness is a restricted and derived version of bodily intentionality. The body is not inert matter but is animate and intentional, for it is an endeavor to continue in its being. This article argues that there is no animism without such intentionality and that Latour's animism will become indistinguishable from mechanism as long as Latour fails to acknowledge animism's intentionality.
\end{abstract}

Keywords Anthropocene $\cdot$ Latour $\cdot$ Agency $\cdot$ Body $\cdot$ Intentionality $\cdot$ Consciousness · Non-human

One of the controversial issues in the discourse on the Anthropocene is the problem of material or bodily agency. Until recently, agency has been the privilege of human consciousness. We have seen ourselves as being ontologically different from nature, as spirit from matter. Such an ontological distinction justified people to use nature as a resource to satisfy their desires. Earth was nothing more than a mere background for human actions and prosperity; however, global warming and climate change, which has grown bad enough to threaten our very existence, has forced us to acknowledge that earth is agential in its own right. What is more alive and active

Jonggab Kim

jonggab@konkuk.ac.kr

1 Department of English, Konkuk University, 120 Neungdong-ro, Gwangjin-gu, Seoul 05029,

South Korea 
than such a global catastrophe? If we bear in mind the current ecological crisis, then we must devise a new theory of agency for recognizing the active role of the nonhumans. Bruno Latour took up the challenge and defined agency as having no element of consciousness or intentionality. His aim was to animate nature-organic and inorganic. To dehumanize agency and animate nature is welcome (albeit late) Anthropocene demand, but Latour's plea to reject intentionality is not only problematic: it contradicts his animistic vision as well. It is one thing to decouple agency from consciousness; it is quite another to decouple agency from intentionality. We have to acknowledge that there is a nonconscious form of intentionality. Latour's mistake is in imagining intentionality in terms of consciousness. More original than our conscious intentionality is bodily intentionality that joins us to the world in our relationship with things around us. The body itself is intentional in that it directs at and affects others, associating or dissociating with them. At the background of conscious intentionality lies bodily intentionality. How can we think of animism without such corporeal intentionality? If Latour dismisses bodily intentionality, then his animism would become indistinguishable from mechanism. This article argues, however, that there is no animism without bodily intentionality.

According to Donna Haraway and Bruno Latour, among other theorists, the body is not inert matter but is the power to affect others and to be affected by them. Without such affectivity, a body would not have any agency. Latour uses "the notion of agency in the sense of "power to act'" (2017, p. 5, emphasis in the original). To act is to "do" things. We should not confuse "do" with "function." If function is neutral and mechanical, then doing implies some form of desire, purpose, and intentionality. Spinoza named it conatus - an endeavor to persist in its being, whether human or nonhuman. But Latour, an advocate of nonhuman agency, insists that "agency [should be] decoupled from [the] criteria of intentionality, subjectivity, and freewill." He believed that these criteria function only to distinguish nonhumans from humans and at the outset dismissed the latter from the membership of agency. To prevent such a human monopoly of agency, he proposed that agency is not a given quality but is that which "modifies other actors through" the course of action (Latour 2004 , p. 75). We should not ask whether agency is human or nonhuman. Such a question is not only irrelevant but also detrimental to our understanding of the exact nature of the agency. An attempt to explain agency in conjunction with intentionality is to presuppose the problem solved. It is necessary to think we do not know anything and to exclude all human preconceptions and start from ignorance. Even to imagine an intention behind a phenomenon interferes with our otherwise neutral and indifferent investigation. It seems that we have no reason to disprove his plea to decouple agency from intentionality. The only problem is that he betrays his methodological demand to begin our investigation without preconception. He does not ask whether there is modality of intentionality other than the human. He does not take bodily intentionality into consideration.

Not all phenomenalists recognize bodily intentionality. For example, John Searle, who represents the internalist perspective of intentionality, defines intentionality in terms of human mental states and understands it as the essential property of human consciousness. He does not acknowledge a nonhuman form of intentionalitynamely, pre-reflexive and material intentionality. Our consciousness is "directed at, 
or about, or of objects and states of affairs in the world' (Searl 1983, p. 1), implying that it has mental contents that are representational and exist independent of the material world. While we direct and relate ourselves to things, matter-though occupying space - is unable to make any meaningful relations. However, though he began phenomenology with such an internalist concept, Husserl later recognized this concept's limitation and tried to extend its scope (Merleau-Ponty 2013, pp. lxxxi-lxxxii). Granted that consciousness pervades most human experiences, there is another form of experience which does not involve consciousness. To explain this phenomenon, Husserl coined the term "operational intentionality" as a contrast and foil for conscious intentionality. Whereas one is mental and internal, the other is bodily (Gallagher 2017, p. 67), which Maurice Merleau-Ponty later called "motor intentionality." Bodily intentionality is extrinsic, material, and non-reducible to mental content. To take the famous example from Martin Heidegger's Being and time, a skillful carpenter does not use a hammer with a conscious effort to hit nails. It is only an untrained novice, who is mentally aware of what he or she is doing, who does so. Most of our casual activities, such as typing and driving, belong to operative intentionality: the fingers of the typist run on the keyboard almost automatically. For Merleau-Ponty, "intentionality is something established already in the natural and pre-predicative unity of the world and of our life" (2013, p. 1xxxii). The typist incorporates the keyboard into his or her bodily movement: she has a corporeal or postural schema for typing. In the absence of such a pre-reflexive unity of the world and life, we could not walk effortlessly or know how to use a hammer. The intentionality of the carpenter is neither autonomous nor independent of the hammer, the wood, or the task at hand: it is both internal and external.

It is this bodily intentionality that we have to bear in mind when we discuss Latour's concept of nonhuman agency. For Merleau-Ponty, bodily intentionality is more primordial and originary than conscious intentionality. Consciousness does not explain or accompany all of our experiences. When a carpenter hammers a nail, her "intentionality" is not mental representation at all, but "skillful bodily responsiveness and spontaneity in direct engagement with the world" (Taylor 2013, p. x). Even our explicit knowledge presupposes our primordial familiarity with the world that is pre-reflexive and embodied (2013, p. lxxx). It is not difficult to find such bodily intentionality, even in primitive forms of life. One classical example is from Jakob Johann von Uexküll, who studied organisms such as ticks and sea urchins and proved their behaviors to be more intelligent than people had usually thought. He maintained that though these tiny animals do not have a brain, they act intelligently. They do not need brains because their bodies themselves are intelligence. Paraphrasing von Uexküll, Giorgio Agamben said that "This eyeless animal finds the way to her watchpoint [at the top of a tall blade of grass] with the help of only its skin's general sensitivity to light" (2003, p. 46). It does not have eyes to see; it is the body that sees. It does not have a brain because it does not need one; the body thinks. The body itself is sufficient for the organism's agency, rendering the brain redundant; the sea squirt, for instance, eats away its own brain if the brain becomes an unnecessary burden. Body is both intentionality and intelligence. However, the internalist conception of intentionality, positing the disunion of interiority and exteriority, cannot account for such bodily intelligence. Moderns (who distinguished the human 
mind from nonhuman materiality) could not account for this entangled unity. Latour regards such an ontological separation as an extreme form of modern hubris. We can believe that if he knew that there is bodily intentionality, then he would have been more cautious in rejecting intentionality altogether. For him, intentionality necessarily includes human consciousness.

From early in his career, Latour took the issue with the notion of agency and has struggled to expunge its anthropocentric association ever since. His actor-network theory (ANT) is one such pioneering attempt. Agency, which he defines as the body's capacity to affect or modify other bodies, neither distinguishes humans from nonhumans nor is in need of intentionality for its action. In Pasteurization of France, Latour demonstrates the inadequacy of intentionality as a model for elucidating the nature of scientific events. Though he highly esteems Pasteur's achievements, Latour does not hesitate to raise the question about whether "the power of his great mind alone" (1988, p. 14) accounts for his solution to the pathogenic microorganisms in certain foods. Scientific achievement is too complex and collective to be attributed to an individual: he or she is a part of vast networks of countless agents, human and nonhuman. Agency is not singular but is distributed and multiple. Latour emphasizes that even the discovery of pathogenic microbes was fortuitous, not the result of Pasteur's studied plan. To explain a scientific event in terms of the intention of a scientist is to beg the question by presupposing the problem solved already without answering it (Latour 2013, p. 77). This explains why Latour loved to quote Rom. 7:19 from the Bible often: "For what I do is not the good I want to do; no, the evil I do not want to do-this I keep on doing." It is not rare that an act one intends for good produces evil consequences. Many agents interfere, distort, and thwart the realization of the plans one intends. Yes, Latour is right. One's intention neither accounts for nor justifies consequences. Nevertheless, to refuse to explain an event in terms of intention is one thing; to untie its relation to agency is another Latour's dismissal of intentionality needs further clarification.

Latour's aversion to intentionality is inseparable from his critique of Cartesian dualism. If one rejects the mind/body dualism, then intentionality will disappear by itself; no mind means no intentionality. In We have never been modern, Latour labored to deconstruct and lay bare modernity's internal contradiction. Descartes separated the universe into two distinct kinds of substances that had no interaction between them. The mind is the thinking substance and is exclusive of and independent from the body. While the mind is self-consciousness, the body is mechanical and obeys natural laws. Ideas, if conceived in the mind as clear and distinct, are necessarily real and true, but bodily perceptions are untrustworthy and misleading. Perceptions, if not purified and disembodied, do not have true value. Because this modern world has no place for bodily intentionality that is both interiority and exteriority, operative intentionality becomes something unthinkable, if not a logical impossibility, like a round rectangle.

Latour contends that Cartesian dualism deprived nature of its agency and animism. Descartes defined matter in terms of extendibility, which itself is quantifiable and measurable: it has length, breadth, depth, weight, and so on. Nature yields itself to modern scientists to be quantified and measured. However, such quantification was impossible for the pre-moderns, since they did not distinguish facts from values 
or the spiritual from the material. To establish modern science, moderns had to leave such a pre-modern world behind and treat nature as the object of experimentation. Nonhuman bodies are inert and function like programmed robots, and their movements obey mechanical laws, but are they really inert? This is the question Latour asks, and his answer is, of course, negative: modern "hardheaded thinkers have invented what should be called inanimism" (2014, p. 10). The Anthropocene demonstrates that the earth, which moderns defined inert, is more alive than anything else. What agent is more animated, energetic, and unpredictable than climate change, global warming, and sea level rise? Indicating those symptoms, Latour observed that the Earth is "quak[ing]! Now it has a subject once again" (2017, p. 61). The agentic power of the earth is an undeniable reality, not a theoretical construction. We hit upon the Real of the earth really hard. The earth, which moderns believed they de-animated and tamed, is animated again with more force than before. Animism is, then, not just an alternative to the modern worldview but is the only legitimate theory that can explain a phenomenon such as earthquakes. Such an emphasis on the earth's agency does not, however, mean that Latour takes it as both animated and intentional. His reluctance to accord intentionality to nature is somewhat surprising, to say the least, if we consider what animism signifies. Animism is a worldview that does not discriminate between animate and inanimate matter. Edward Tylor in Primitive culture defined animism as "a belief in personal souls animating even what we call inanimate bodies" (1871, p. 31). All bodies for him, whether human or nonhuman, have life and will. Embracing such a vital vision of nature, Jane Bennett intended to substitute the concept of "thing" with "thing-power": things have "propensities, or tendencies of their own" (2010, p. viii). They do not passively succumb to human desire for control but resist subjugation. Animals, plants, and stones are bodies as energetic and intentional as humans, though in different ways. Whether human or nonhuman, animate or inanimate, all bodies endeavor to preserve their being, but Latour does not take such universal desire for survival into consideration when he discusses agency.

All bodies, humans or nonhuman, are conatus in their essence. Conatus signifies the power of the body to act "alone or in conjunction with other things [...] to persist in its being" (Spinoza 2002, pp. iii, vii). All bodies with capacities to affect or be affected tend to associate with or disassociate from one another to increase and intensify their conatus. Here intention is bodily and pre-reflexive: for ticks and sea urchins, the body is intentionality and intelligence. Such embodied intention is not very different from Aristotle's concept of plant and animal souls: a plant has a vegetative soul and an animal a sensitive soul. Their souls aspire to grow and propagate. Phototropic plants spread their leaves toward the sun and take root toward water in the soil. Aristotle found in those plants and animals a teleology that is unthoughtful but operational. ${ }^{1}$

\footnotetext{
1 Most scholars of Spinoza do not regard conatus as teleological, but Don Garrett argued that it is teleological to the extent it is an endeavor to exist (1999, p. 313). Using Aristotle's categories of cause, it is clear that conatus is teleological in terms of efficient cause, not of final cause.
} 
It is exceedingly problematic that Latour refuses to grant intentionality to material agency. For both Aristotle and Tylor, as well as for Spinoza, all bodies, human or nonhuman, desire survival. What they do, affecting and being affected in alliance with others, has meaning in that it concerns their survival or extinction. Life or death is inseparable from their agency. But Latour, even when he elaborates about animism, seems reluctant to refer to survival or life. Indeed, Latour's ontology is relational and collective: the body with more connections to other bodies is more real and agentic than bodies with fewer connections or assemblages. The body is not an entity but a process of becoming more or less affective. As there is no individual body without assembly, so there is no assembly without the individual body. As Haraway, Bennett, and Alaimo have argued, the body is not self-enclosed but porous and dynamic, and its boundaries can be crossed. Such relational ontology, which Latour also supports, partially accounts for his rejecting intentionality. Nonetheless, it is worth noting that his project of debunking modernity requires him to discredit intentionality: Latour conceived of intentionality as the outcome of the modernist decision to separate mind from body and the animate from the inanimate. The mind/ body dualism postulates intentionality as the essential component of the human mind. In Latour's conceptual scheme, modernity stands in symmetrical opposition to the pre-modern worldview, as animation to de-animation.

Latour's effort to revive animism is another part of his criticism of modern humanism. Modernity for him signifies the drastic gesture of separation and differentiation between interiority and exteriority. Separation combined with the modern intention to break away from the pre-modern represents disjunction, de-animation, differentiation, hierarchy, categorization, segregation, purification, and so on. Latour tried to deconstruct and then to reconstruct those concepts contaminated by the modern desire for hierarchical differentiation. Flat ontology, a total democracy of things and bodies, is his answer to such a demand for conceptual reconstruction. In Reassembling the social, he emphasizes repeatedly and with urgency the necessity of "flattening the landscape" (2005, p. 183, 189, 192, 205, to cite a few instances). Such a flattening for him is a necessary virtue for scholars who want to know what really happens in events: they should forsake any preconceived concepts about the value and meaning of things that they investigate. He sets his heart on "making flatness as the default position of the observer" (2005, p. 220). This default position does not acknowledge in advance differences between human and nonhuman, between animate and inanimate, intentionality and non-intentionality. However, it is worthwhile observing that flattening can take the form of either upward or downward movement. The flattening between animate and inanimate can make landscape entirely animate or inanimate, all intentional or non-intentional. What happens if the bar separating animate and mechanistic falls? Is this flat world universally animistic? Does animism become identical with mechanism if the difference cancels itself out? It is not groundless to suspect that Latour's version of animism verges on mechanism.

Latour's conflation of the organic and the mechanical can jeopardize his proposal to understand nature as animate. Eduardo Kohn in How forests think comments that Latour's "lumping together things and beings" is "the biggest shortcomings of STS [science and technology studies]" (2013, p. 91). The attempt to 
completely pull down the division can result in the opposite of one's intention. If one extends the scope of animism further and further, then finally one arrives at a point at which animism loses its original meaning. Hegelian dialectic conceptualizes such reasoning as the unity of opposites: good coincides with evil, and vice and life and non-life are identical. It seems that Latour is aware of such a paradox. For example, he proposes a thought experiment, asking "What happens in fact if you extend intentionality to all agents?" His immediate answer is that "Paradoxically, such an extension quickly wipes out all traces of anthropomorphism" (2013, p. 99). But there is no paradox here. Paradox does not inhere in such an attempt to extend but is generated when we couple intentionality with anthropomorphism. Animism in itself is not anthropomorphic. From the fact that all things and bodies are intentional, it does not follow that animism becomes indistinguishable from mechanism. We do not know how to account for the animism present in inorganic matter such as stones and machines. However, we need to take note that there is a significant difference in material intentionality between stones and animals. Although all bodies without exception equally strive to exist, there is a broad spectrum of differences in their conatus, and they are singular in their ways. Latour's conflation of the organic and the mechanical ignores such a difference constitutive of animism, and it is vital to remember, as we have seen, that there is no animism without bodily intentionality.

Latour's concept of intentionality in terms of human consciousness led him not only to reject it without further consideration but also to define animism mechanically. There is no doubt that his characterization of modernity as opposed to premodernity is responsible for his decision to drive out intentionality from agency. He blamed the moderns for their monopoly of agency and their exploitation of nature. No one will disagree with his proposal to reject modern anthropocentrism and to acknowledge nonhuman agency. However, intentionality is not necessarily human; pre-moderns regarded animals and plants as being as intentional as themselves. If he did not conjoin intentionality with consciousness, then Latour would have recognized the presence of preconscious and bodily intentionality that is both mind and body. It is paradoxical that the operational intentionality, which he failed to acknowledge, kept on coming back to possess him repeatedly whenever he claimed that the moderns had never been moderns. The moderns intended to separate themselves from the pre-modern worldview but instead succeeded in generating hybrids, both modern and pre-modern. Bodily intentionality is one such hybrid. The body is not only animate but intentional as well. It would be unthinkable to envisage animism without corporeal struggles. Is not it enough to dehumanize agency by decoupling it from consciousness? We do not need to decouple animism from intentionality: to do so would be to conflate it with mechanism.

Acknowledgements This paper was supported by the Konkuk University, the Ministry of Education of the Republic of Korea, and by the National Research Foundation of Korea (NRF-2017S1A5B8057457).

Open Access This article is licensed under a Creative Commons Attribution 4.0 International License, which permits use, sharing, adaptation, distribution and reproduction in any medium or format, as long as 
you give appropriate credit to the original author(s) and the source, provide a link to the Creative Commons licence, and indicate if changes were made. The images or other third party material in this article are included in the article's Creative Commons licence, unless indicated otherwise in a credit line to the material. If material is not included in the article's Creative Commons licence and your intended use is not permitted by statutory regulation or exceeds the permitted use, you will need to obtain permission directly from the copyright holder. To view a copy of this licence, visit http://creativecommons.org/licen ses/by/4.0/.

\section{References}

Agamben, G. (2003). The open: Man and animal. Redwood City: Standard University Press.

Bennett, J. (2010). Vibrant matter: A political ecology of things. Durham: Duke University Press.

Gallagher, S. (2017). Enactivist interventions rethinking the mind. Oxford: Oxford University Press.

Garrett, D. (1999). Teleology in Spinoza and early modern rationalism. In R. Gennaro \& C. Huenemann (Eds.), New essays on the rationalists (pp. 310-335). New York: Oxford University Press.

Kohn, E. (2013). How forests think: Toward an anthropology beyond the human. Berkeley: University of California Press.

Latour, B. (1988). The pasteurization of France (A. Sheridan \& J. Law, Trans.). Cambridge: Harvard University Press.

Latour, B. (2004). Politics of nature: How to bring the sciences into democracy (C. Porter, Trans.). Cambridge: Harvard University Press.

Latour, B. (2005). Reassessing the social: An introduction to actor-network-theory. Oxford: Oxford University Press.

Latour, B. (2013). An inquiry into modes of existence: An anthropology of the moderns. Cambridge: Harvard University Press.

Latour, B. (2014). Agency at the time of the Anthropocene. New Literary History, 45(1), 1-18.

Latour, B. (2017). Facing Gaia. Eight lectures on the new climatic regime (C. Porter, Trans.). London: Polity.

Merleau-Ponty, M. (2013). Phenomenology of perception (D. Landes, Trans.). London: Routledge.

Searl, J. (1983). Intentionality: An essay in the philosophy of mind. Cambridge: Cambridge University Press.

Spinoza, B. (2002). Ethics. In Complete works (S. Shirley, Trans.). New York: Hackett.

Taylor, C. (2013). Foreword. In Merleau-Ponty, M. (2013). Phenomenology of perception (D. Landes, Trans.) (pp. vii-Xvi). London: Routledge.

Taylor, E. (1871). Primitive culture (Vol. II). London: John Murray.

Publisher's Note Springer Nature remains neutral with regard to jurisdictional claims in published maps and institutional affiliations. 